\title{
Human Capital and Its Impact on Promoting the Knowledge Economy "Saudi Arabia as a Model"- An Applied Study During the Period (2010-2020)
}

\author{
Safa Mohammed Elhassan Younis ${ }^{1}$ \\ ${ }^{1}$ College of Business, University of Jeddah, Al-Kamel Governorate Branch, Jeddah, Saudi Arabia \\ Correspondence: Safa Mohammed Elhassan Younis, College of Business, University of Jeddah, Al-Kamel \\ Governorate Branch, Jeddah, Saudi Arabia. E-mail: smyounis@uj.edu.sa
}

Received: December 11, 2020

Accepted: January 1, 2021

Online Published: January 27, 2021

doi:10.5430/rwe.v12n2p186

URL: https://doi.org/10.5430/rwe.v12n2p186

\begin{abstract}
The study is an attempt to measure the impact of human capital in promoting a knowledge economy by applying it to the Kingdom of Saudi Arabia set during the period from 2010 to 2020. In order to achieve the objectives of the study, the researcher began with a simple narration of the theoretical aspect of the topic to derive benefit from the theoretical background concerning the study of the study variables.
\end{abstract}

Keywords: knowledge economy, human capital, Saudi Arabia, information society, skillsets

\section{Introduction}

With the transformation of the knowledge economy, many changes have occurred in the work environment and administrative concepts in general, and human resources. The most important change witnessed is the interest in human capital rather than in physical capital. The interest in human capital has increased in today's competitive and dynamic work environment, especially with the increase in the role and value of knowledge in work, and the tremendous technological developments. The latter has imposed many challenges on companies and led to major transformations in the patterns and methods of work. Also, competition in the era of the knowledge economy has led to a shift away from a focus on investment in material resources to the efficiency and development of the human element, through human investment. Of late, human capital has become the most important economic resource, due to what is tired of its rare characteristics and the difficulty of imitating it. Besides, it is a unique, reliable tool, and plays an important role in improving performance and registering the growth of institutions. Remarkably, human capital is difficult to imitate by some competitors as it represents a group of activities and processes impacting the minds of the employees within an organization. Efficient and knowledgeable human capital provides sustainability and a competitive edge to organizations and countries, given their diversely rich and relevant skillsets and capabilities that may enable countries to achieve economic success and leadership. A responsible labor market is extremely competitive (Ramedi Bassam, Malwa Mariam, and Salami Asma, 2018). So, human capital has gained currency by utilizing knowledge and achieving its goals. Devising effective methods to develop experienced, knowledgeable, and innovative Human money that can achieve excellence and reduce gaps in scientific and cognitive abilities poses a challenge for organizations and countries.

\section{Previous Studies}

The following is a summary of some studies dealing with some aspects of the topic:

The study by (Dawi Sheikh and Hamdi Abu Al-Qasim, 2013) entitled: The role of human capital development in the integration of organizations in the knowledge-based economy aimed to analyze ways of developing human capital as one of the main components of intellectual capital within the framework of a comprehensive strategy. It allows business organizations to effectively integrate into the knowledge-based economy and highlight the benefits accruing to business organizations after adopting a suitable strategy for developing their human competencies.

During the stage of organizational maturity within the framework of the life cycles, the information economy forces organizations to provide an organizational climate that stimulates education and creativity in a way that guarantees them a successful integration and prepares them to enter the bioeconomic stage based on knowledge by 2030 and 
adapting them to its facts and circumstances. The study concluded that if business organizations want to develop their competencies and ensure the best investment in their human capital, they must promote a knowledge-based economy, which may enable these organizations to adapt to the data and conditions of this new vibrant economy.

The study by (Annaba and Qawsi Samira, 2019): Availability of the first human capital in the knowledge economy A field study in the Regional Directorate of the Algerian Company for Insurance and Reinsurance (CAAR) at Annaba aimed to understand the availability of the dimensions of human capital in the Regional Directorate of the Algerian Company for Insurance and Reinsurance CAAR at Annaba. In it, a sample form was distributed to 67 employees and 55 forms were received from the respondents. Some of them were valid for analysis; statistical analysis of data indicated adequate availability of human capital in the research directorate at Annaba, Algeria. The study highlighted that the interest in human resources was not limited to considering them as a resource only. It underlined the need to pay attention to the value of human capital, which should be reserved as it is considered the main source of competitive advantage for enterprises.

\section{The Theoretical Framework of the Study}

\subsection{The Economic Importance of Human Capital}

The accumulation of human capital is the second important component in terms of contributing to growth, and there is a consensus that human capital is the most important and one of the main determinants of economic development. It is also termed as the information economy since the most important productive elements can help achieve economic development with proper education since education contributes to the accumulation of human capital. Theories of economic growth have highlighted that technological progress increases the rate of long-term economic growth, and technological progress increases rapidly when the workforce is more educated; hence, the accumulation of human capital aids in technical progress and is considered a source of sustainable growth (Hanushek and Woessmann 2010). Therefore, the development of human resources has become one of the most important and pressing imperative to surge ahead in the global arena. It facilitates proper mobilizing, qualifying, and developing capabilities and human competencies in their scientific, practical, technical, and behavioral aspects (Ahmed, Navas Ayoub Muhammad Ali, 2010).

\subsection{Conceptual Framework for the Idea of Investing in Human Capital}

It is believed that education is the primary factor in increasing human capital. Recent years have witnessed an increasing interest in an intensive research program to invest in human capital. T.W. Shultz is considered a pioneer in the spread of education worldwide. Investments in human capital involve significant costs for the organization; labor costs include the salaries and other spending in favor of employment maintenance, retraining, and development of employees (Adnan Saidi, 2017).

\subsection{The Components of Investment in Human Capital}

\subsubsection{Education}

Generally, education contributes to the improvement and development of human resources by raising competence and mental capacity and the absorption capacity and raising the productivity of the various sectors of the economy (United Nations, 2007). Individual economist Marshall referred to the economic value of education, as he emphasized a wide variety of capital investments that invest in people, improve the personal efficiency of individuals, and search for the benefit of them, and from Malish's point of view the lack of education makes people poor and the poverty makes them unhappy. Khiri (Johnstewartmill) argues that economic and social reforms depend on education and are urgently needed. Dissemination of knowledge to improve the quality of human beings makes them more in control of the directions of their activities. Earlier, mankind and the education of humans formed important elements of the capital stock. In a knowledge society, a strong association between economic development and education has been established in achieving the twin goals of wealth generation and technological developments. They meet the needs of the national economy and expand the knowledge area of society (Sundus and Shatha, 2018).

\subsubsection{Training}

McClelland (2002) defined training as the activity that changes the behavior of individuals; is part of human resource development and is linked with other human resource activities such as recruitment, selection, and compensation. Adequate education and training have proven useful in dealing with technological change and enhancing productivity in manufacturing industries. Ultimately, the training leads to the uniqueness of the human capital of the organization in which it works and increases relevant experience that cannot be obtained in the open labor market. Many studies have asserted that training is the manager's responsibility because the training aims at developing 
better capabilities of employees. Sahanin Meloud and Dani El Kabir Amcado (2017) opined that training is not only a means of developing skills but also a tool for socialization.

\subsubsection{Research and Development}

Research and development is the basic activity of states in achieving development and ensuring effective participation in civilized progress. A well-qualified person plays a significant role in stimulating research in terms of generating, transferring, and exploiting scientific knowledge where research plays its role in developing human competencies and providing returns that ensure proper growth of economic and social development comprehensively. A high level of research and development in the knowledge economy is considered an indicator of lower inequalities and disparities in developed and developing countries. It is primarily attributed to investing in scientific research and applying its results in all development sectors. Investing in research and development becomes important as it contributes to developing knowledge and technical skills based on scientific research. It is applied in different walks of life and the same economic, production, and service and others, in a way that leads to increasing the wealth of society, increasing the productivity of the economy, improving the quality of production and the ability to compete with others, for both the individual and the state (Sundus and Shatha, 2018).

\subsection{The Concept of the Knowledge-Economy}

The knowledge economy, "new economy" or the "information economy" relates to the knowledge-based economy, both directly and indirectly. Within this framework, the main engine of economic growth - the knowledge economy depends on the availability of faster communication technology, information, innovation, and digitization to produce high value-added goods and services. In this framework, "knowledge" can be defined as the knowledge economy, "new economy," "information economy," or "knowledge-based economy", whether directly or indirectly. Knowledge in this framework is considered the main engine of economic growth; knowledge economies depend on the availability of high-tech communications and information technology, and the use of innovation services. In this context, "knowledge" can be defined as the last stage of the transformation of data into information through the availability of a possible knowledge environment surrounding this transformation under the necessity of the existence of an interconnected organic relationship between data, information, and knowledge (Nurunnabi, 2017).

The knowledge economy can also be defined as "an economy based on the creation, valuation, and circulation of knowledge, in which labor costs gradually become less important and traditional economic concepts such as scarcity of resources, economics, and the extent of their application." Sahanin Meloud and Dani El Kabir Amcado (2017) has defined it as "production and services based on knowledge-intensive activities and the acceleration of the pace of technology that contributes to this.

\subsection{Requirements for Integration Into the Knowledge-Economy}

The process of transformation from a traditional economy to a knowledge economy based primarily on knowledge and human capital requires the availability of two basic conditions, namely establishing advanced technological structures and investing in human capital. The requirements for integration into the knowledge economy can be further described as under:

\subsubsection{Information and Communication Technology (ICT)}

Adequate investment in information and communication technology, such as the software industry is required in the manufacture of automated media equipment. ICT helps integration into the knowledge economy. It relates to knowledge about the process of sharing and transferring it easily, avoiding the duplication of searching for new knowledge. Information and communication technology is considered to be most instrumental in achieving economic growth, preserving knowledge as a credit, or as an identifier, in its explicit and specific aspect, for example in the form of patents, databases, and systems information. (Kamal Mansouri, Issa Khalifa, 2006).

\subsubsection{Education}

It is viewed as a productive, developmental, and long-term investment process, and forms the backbone of progress. Society is the main organ for evaluating human resources. The level of performance of organizations, in general, depends on the efficiency of employees as education raises the efficiency, development, and ability of the human element to utilize the knowledge and modern technologies, which make the process of spending on education inevitable (Kanda Zelikha and Bouqum Mohammed, 2018).

\subsubsection{Research and Development}

Scientific research and development are important as it contributes to the development of scientific and technical knowledge. It leads to increasing the productivity of the economy, increasing competitiveness, and developing the 
quality of human money and personnel capabilities, especially in non-material areas such as information, and software. Integration of research and development into the knowledge economy requires drawing the attention of a scientific research center and raising the proportion of spending on projects research and development and linking the results of scientific research and development to practical reality to achieve beneficial and tangible results. On the other hand, the development of education in a quantitative and varied manner encourages technological research and development, especially what is related to the advanced technical areas that are included in the knowledge economy (Kanda Zelikha and Bouqum Mohammed, 2018).

\subsection{Knowledge-Economy Index (KEI)}

A knowledge economy index is based on the availability of an enabling environment for knowledge to be used effectively for sustainable economic development. Thus, along with the importance of knowledge generation, and the primary role of knowledge accumulation and the ability to innovate, KEI should be used in economic development since the knowledge-based economy index is based on a total indicator representative of that level. The overall development of the state towards a knowledge economy. According to KEI, the knowledge economy is based on four main elements, that is, three knowledge indicators: science and technology, education and human resources, and the innovation system, and the fourth indicator for technical applications: information and communication technology (ICT). The knowledge economy index is calculated based on average scores (points) of the country's standard performance concerning all four pillars of the knowledge economy (Ahmed, 2014). The following is a simple explanation of the main indicators that make up the knowledge economy index:

\subsubsection{Science and Technology Indicators}

They are related to research, statistics, patents, scientific publications, technology, the balance of payments, and some indicators of information dissemination and communication. They deal with expenditure on research and development, sources of financing, the number of patents registered, and the number of scientific publications.

They reflect the state's interest in the knowledge economy as they explore the quest of researchers to develop their capabilities and develop the economy. They also include the balance of payments technology, the purchase, and sale of unmodified technology such as intellectual property rights, licenses, and technical assistance (Sundus and Shatha, 2018).

\subsubsection{Human Resource Indicators}

Everyone recognizes the importance of the variables related to human resources in the knowledge economy. Some well-known indicators to study this dimension of the knowledge economy are important as they measure the competencies of individuals.

Education, training, and human capital stocks are the two main sources of human resource indicators.

\subsubsection{Indicators of Dissemination of Information and Communication Technology}

With the emergence of new information and communication technology, the knowledge-based economy has led to an adequate technological base, strengthening of intense activities in knowledge, production, and diffusion of new technology and resultant positive consequences for the economy. Fundamental to the knowledge economy, this is the basis for innovations in services and products throughout the economy (Sahanin Meloud and Dani El Kabir Amcado, 2017).

\subsection{The Impact of Human Capital in Promoting the Knowledge-Economy}

\subsubsection{Investment in Human Capital Is a Necessity in a Knowledge-Economy}

The increased interest in human capital with the technological development that has taken place in the world and the accompanying urgent need for a skilled and specialized workforce and intensive capital investment in the development of human capacities has been a prelude to the transformation to a knowledge economy. Human capital is the backbone of the knowledge economy and the key to the success of the overall and sustainable development process and is one of the important indicators for measuring the knowledge economy (Amal, Suad, and Sands, 2014).

In the knowledge economy, human capital has become a strategic resource that is an effective force for this economy and the main source of wealth and prosperity. It is valuable to the organization, can be easily imitated, and is an irreplaceable resource, characterized by scarcity of diverse experiences, skills, and knowledge that enable it to increase innovations and innovations accelerated in record time and the modern business environment (Nasser and Samira, 2016). The economy of knowledge requires qualified and trained human resources and is characterized by a high level of education, training, and implementation in practical situations. It must be trained in accordance with 
modern technological developments, trained in adaptation in order to obtain global information in the easiest and simplest ways, and must be careful to grow professionalism, continuous self-learning, knowledge reception, and development by the working environment. Its ability to solve problems; devise solutions, help decision-making is characterized by the ability to switch from one profession to another, as well as the ability to deal with technology in its various forms and employ it successfully.

There are many financial measures to invest in human capital. Business organizations must follow and strengthen human capital for a shift towards a knowledge economy. Most importantly, they should enhance the total expenditure on education, through which the funds are allocated by the state to develop the educational process of the current era. Besides, organizations cannot ignore the expenses of vocational training allocated before, as well as spending on training and opening specialized institutes within certain disciplines and centers. It helps universities to develop the curriculum under the spirit of the companies under which research and patents are spent in order to develop the staff and develop production plans to reach high and advanced levels of productivity.

The overall developments in the economic, social, and even political life require companies and institutions to work on developing human cadres as they are considered an inexhaustible stock. On the contrary, their production can increase in the long run considering continuous rehabilitation (Nadia and Hashem, 2013.)

3.7.2 The Role of Investment in Human Capital in Promoting the Integration of Countries Into the Knowledge-Economy

The field of modern technological infrastructure: Human capital contributes to modern technological infrastructure in several ways such as:

- Knowledge workers are considered important components of human capital and their contribution to the generation, acquisition, localization, and transfer of technology in its information and communications aspects is clear. No country can achieve this robust technological structure without mobilizing its human structures and cadres, so if it wants to transfer or localize technology, it will achieve this by knowledge workers.

- Reliance on value-based human capital helps enrich the technology system by achieving so-called electronic activities, and therefore the rehabilitation of the human element by investing in it to accommodate new ICT applications that enables to large extent activities such as electronic management, e-government, and electronic organizations, etc.

The field of the creative system: It is known that the adoption of many organizations in the development of human capital on training activities contributes to the development of the spirit of creativity among individuals. Therefore, we can say that the components of the national innovation system are not upright except in the availability of business organizations that encourage creativity among individuals, and this is inevitably reflected in patents, registration rights, and licenses that benefit the organizations and the national economies.

Education and training systems: Education and training should not be limited to the scope of business organizations, but it must be extended both before and after employment also to take life-long care of human capital.

Good governance: The openness of organizations to face reality and emerging changes in their surroundings and their parallels confirm that they are already moving at a steady pace towards ensuring good governance in all areas, at their level or even at the level of governments and macro policies.

From the above, it can be inferred that human capital is the mainstay of private organizations seeking excellence and leadership. Human capital is a source of knowledge and generation. It contributes to achieving the overall strategic objectives, particularly the goal of integration into the knowledge economy (Dawi Sheikh and Hamdi Abu Al-Qasim, 2013).

\subsection{Saudi Arabia's Experience of the Shift Towards a Knowledge-Economy}

The Saudi economy is considered as one of the strongest in the Yat region; the KSA is the largest oil exporter in the world. It is known that the planning of the Saudi economy was largely based on oil revenues for a period of nearly forty years (1970-2010) according to some statistics. That's why Saudi leaders have exploited these favorable conditions, diversified the sources of their economy, shifted towards the knowledge economy, and have supported it.

In this context, many efforts have been made to move towards the knowledge economy in the KSA. Some of these are as under In 2011, the plan for university education was adopted to achieve a future vision for building a knowledge society in the Kingdom. 
Adopting the strategy of talent, creativity, and support for innovation - Vision 2020.

- The Knowledge-based Economic conference and its role in national development (2014) recommended that the Kingdom should shift towards the knowledge economy.

- The role of universities in the knowledge economy has shifted from its first function of providing specialized education services to a more important function to meet the requirements of the transformation of the knowledge society, namely the transfer of technology, promotion of innovation, contribution to continuing education and community partnership (Nayef, 2018).

- The Kingdom has launched the Reform Program 2016-2030, 2030), an ambitious reform program that allows Saudi Arabia to diversify its economy and minimize its dependence on oil, and to make a qualitative leap in the economy of the 21st century (Maggie, 2019).

\section{Research Design}

\subsection{Problem Statement}

Human capital now represents one of the fundamental prerequisites for a smooth transition towards a knowledge economy. This requires exploring ways and means that allow the investment of the knowledge and skillsets in human capital. Accordingly, the problem of this study is to find out what is the impact of human capital on enhancing the knowledge economy in a Saudi Arabia setting?

\subsection{Importance of the Study}

This study assumes significance as human capital is a key asset to any organization due to its diverse capabilities and skillsets. The economists consider it as the first ingredient for enhanced productivity and they have termed it as an essential and necessary condition for transition to a better society and the knowledge economy.

\subsection{Objectives of the Study}

The study aimed to measure and estimate the effect of human capital to promote the knowledge economy in the Kingdom of Saudi Arabia as a model for study. Also, it sought to achieve a set of goals such as familiarity with the concept and components of a knowledge economy and measuring the rate of growth in the knowledge economy index (KEI) and human capital index (HCI).

\subsection{Study Methodology}

The descriptive method and statistical analysis were employed by utilizing the available data on the Human Capital Index and the Knowledge Economy Index in the Kingdom of Saudi Arabia. It was conducted for the period from 2010-2020 to measure and test the impact of human capital in promoting the knowledge economy in KSA.

\subsection{Hypothesis}

The study is based on one basic hypothesis It is hypothesized that there is a positive effect of human capital in KSA in promoting and supporting the integration of organizations/countries into the knowledge economy.

\section{The Applied Framework of the Study}

It includes measuring the impact of human capital in promoting the knowledge economy in Saudi Arabia studied from 2010 to 2020, to investigate the hypothesis that human capital plays an important role and a positive moral impact in promoting the knowledge economy.

\subsection{Research Methods}

\subsubsection{Variables in the Study}

It employed two variables: knowledge economy index (KEI) as a dependent variable, and the human capital index (HCI) as an independent variable.

\subsubsection{Data Collection Method}

In this study, data on the two variables: HCI and KEI of study in Saudi Arabia were collected. It relied on the data obtained from the Arab Knowledge Report for different years as well as the World Bank database for different years, in addition to the Human Development Report for different years, covering the study period from 2010-2020.

\subsubsection{Statistical Methods Used in the Analysis}

We analyzed the data using the statistical program (SPSS). The analysis included evaluating correlation coefficients using the Pearson correlation coefficient to determine the strength and direction of the relationship between the study 
variables in order to verify the design of the model and the sincerity of the duties.

\subsubsection{Contrast Analysis of Simple Slope Using Test}

- Correlation coefficients using the Pearson correlation coefficient to calculate the strength and direction of the relationship between the variables of the study.

- Contrast analysis of simple slope using a test F.

- Analysis of simple linear regression to illustrate the relationship between the dependent and independent variable and determine the degree of impact between them, in addition to t-tests

- Analysis of the overall trend and growth of both the human capital index variable and the knowledge economy index

\section{Results, Analysis, and Discussion}

First: The strength of the relationship and the degree of association between the two variables of the study were measured using the Pearson correlation coefficient during the study period and the results were as in the following Table 1.

Table 1. Pearson correlation coefficient measurement correlations

\begin{tabular}{|c|c|c|c|}
\hline & & $\begin{array}{l}\text { Knowledge-Economy } \\
\text { Index }\end{array}$ & $\begin{array}{c}\text { Human } \\
\text { Capital Index }\end{array}$ \\
\hline \multirow{3}{*}{$\begin{array}{l}\text { Knowledge-Economy } \\
\text { Index }\end{array}$} & Pearson Correlation & 1 & 0.750 \\
\hline & Sig. (2-tailed) & & 0.008 \\
\hline & $\mathrm{N}$ & 10 & 6 \\
\hline \multirow{3}{*}{$\begin{array}{l}\text { Human } \\
\text { Index }\end{array}$} & Pearson Correlation & 0.750 & 1 \\
\hline & Sig. (2-tailed) & 0.008 & \\
\hline & $\mathrm{N}$ & 6 & 10 \\
\hline
\end{tabular}

Table 1 shows the moral relationship between human capital and the knowledge economy index in Saudi Arabia, where the morale score was 0.008 , and there was an error rate of 0.01 and at a degree of confidence $99 \%$, which indicates the strength of the relationship between HCI and KEI.

The current study also highlights a correlation between human capital and the knowledge economy, where the value of the link is 0.750 , which is a very strong and exorcist link, which shows that investment in human capital could strengthen the knowledge economy in KSA

Second: the contrast analysis test which can be summarized in table 2 .

From the analysis of the contrast above, since the moral level $=0.008$ less than 0.01 , in this case, is rejected, and we accept the imposition of the alternative which provides for a moral relationship and a $99 \%$ confidence in the building of human capital and the knowledge economy in Saudi Arabia during the study period.

Third: Analysis of the general trend and growth rate of both HCI and KEI

Table 2. Analysis of the contrast between human capital and the knowledge economy

\begin{tabular}{|c|c|c|c|c|c|c|}
\hline \multicolumn{7}{|c|}{ ANOVA } \\
\hline Model & & $\begin{array}{l}\text { Sum of } \\
\text { Squares }\end{array}$ & Df & Mean Square & $\mathrm{F}$ & Sig. \\
\hline 1 & Regression & 1914.745 & 1 & 1914.745 & 5.134 & $0.008^{\mathrm{b}}$ \\
\hline & Residual & 1491.936 & 4 & 372.984 & & \\
\hline & Total & 3406.681 & 5 & & & \\
\hline
\end{tabular}

A. Dependent Variable: Knowledge-Economy

b. Predictors: (Constant), Human Capital economy

Source: Prepared by the researcher based on the results of the statistical analysis. 
Table 3. The general trend and growth rate of the knowledge economy index data in Saudi Arabia

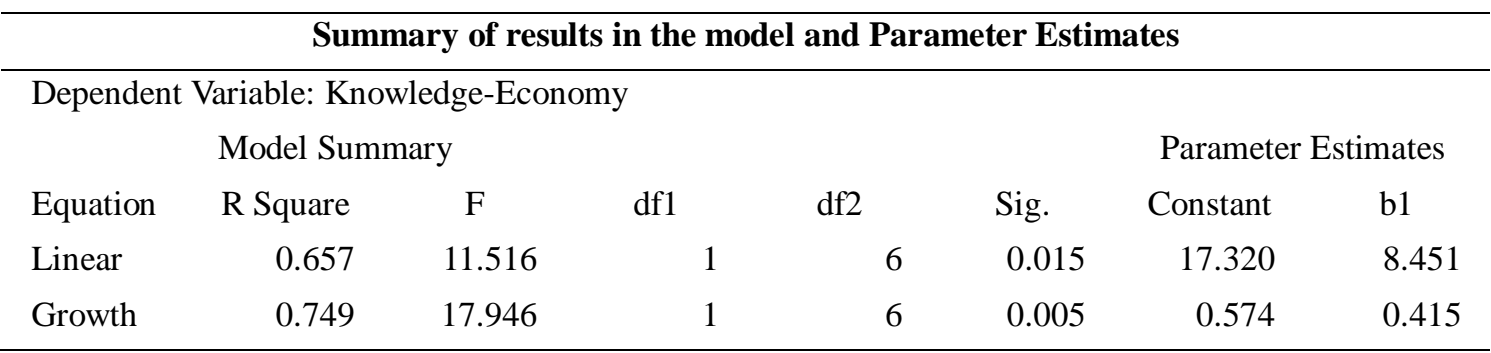

Source: Prepared by the researcher based on the results of the statistical analysis.

The above data (table 3) reveals that the Knowledge Economy Index (KEI) in Saudi Arabia registered an annual increase of 8.451 and growth at a rate of 0.415 per year and can be shown graphically as figure 1 .

Table 4. The general trend and growth rate of human capital index data in Saudi Arabia

\begin{tabular}{|c|c|c|c|c|c|c|c|}
\hline \multicolumn{8}{|c|}{ Model Summary and Parameter Estimates } \\
\hline \multicolumn{8}{|c|}{ Dependent Variable: Human Capital } \\
\hline & \multicolumn{4}{|c|}{ Model Summary } & \multicolumn{3}{|c|}{ Parameter Estimates } \\
\hline Equation & R Square & $\mathrm{F}$ & df1 & df 2 & Sig. & Constant & b1 \\
\hline Linear & 0.980 & 245.709 & 1 & 5 & 0.000 & 2.480 & 0.028 \\
\hline Growth & 0.978 & 220.044 & 1 & 5 & 0.000 & 0.909 & 0.011 \\
\hline
\end{tabular}

Source: Prepared by the researcher based on the results of the statistical analysis.

The above data (Table 4) shows that the HCI in Saudi Arabia increased annually by the equivalent of 0.028 and grows at a rate of 0.011 per year, as shown in Figure 2.

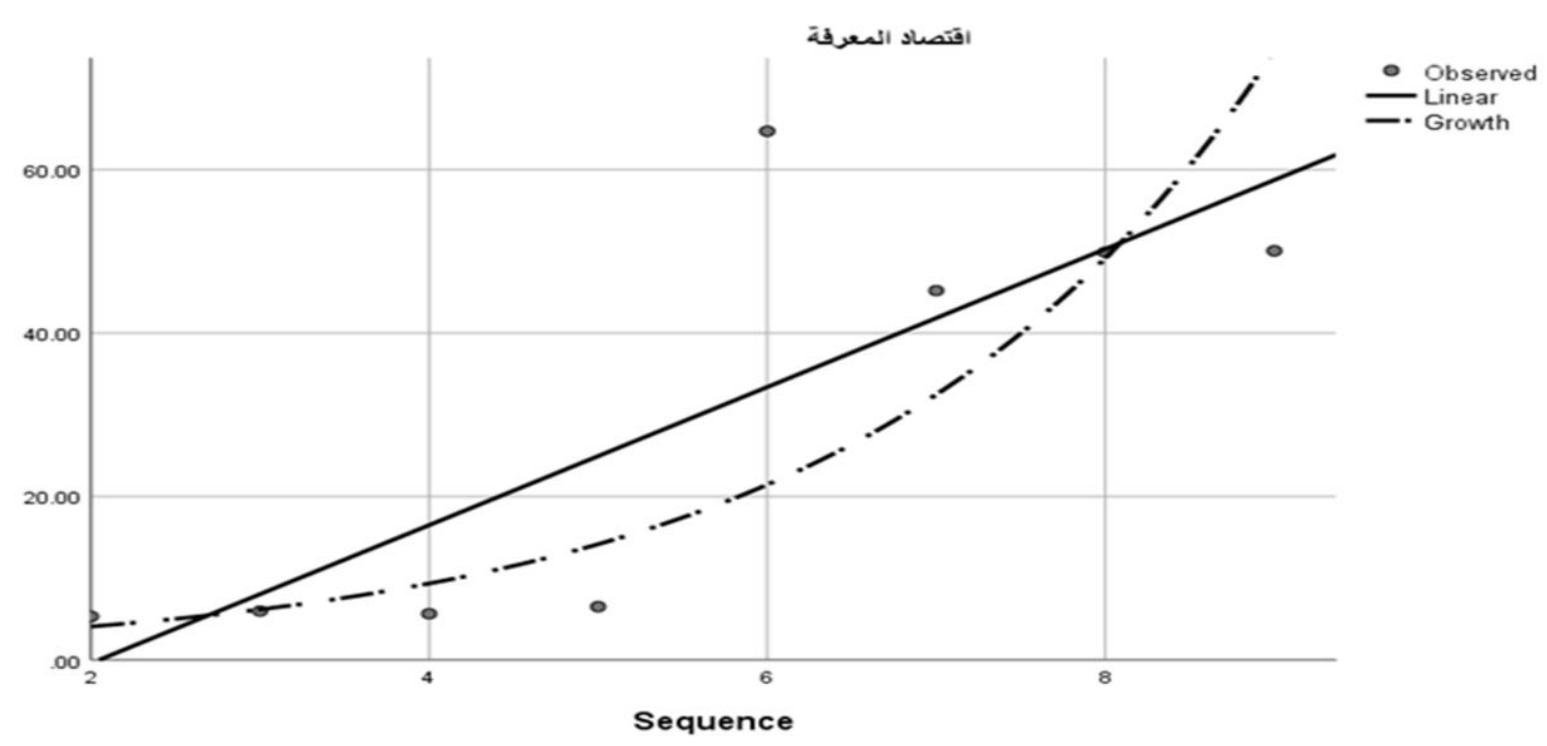

Figure 1. Growth and direction of knowledge economy index from 2010-2020 


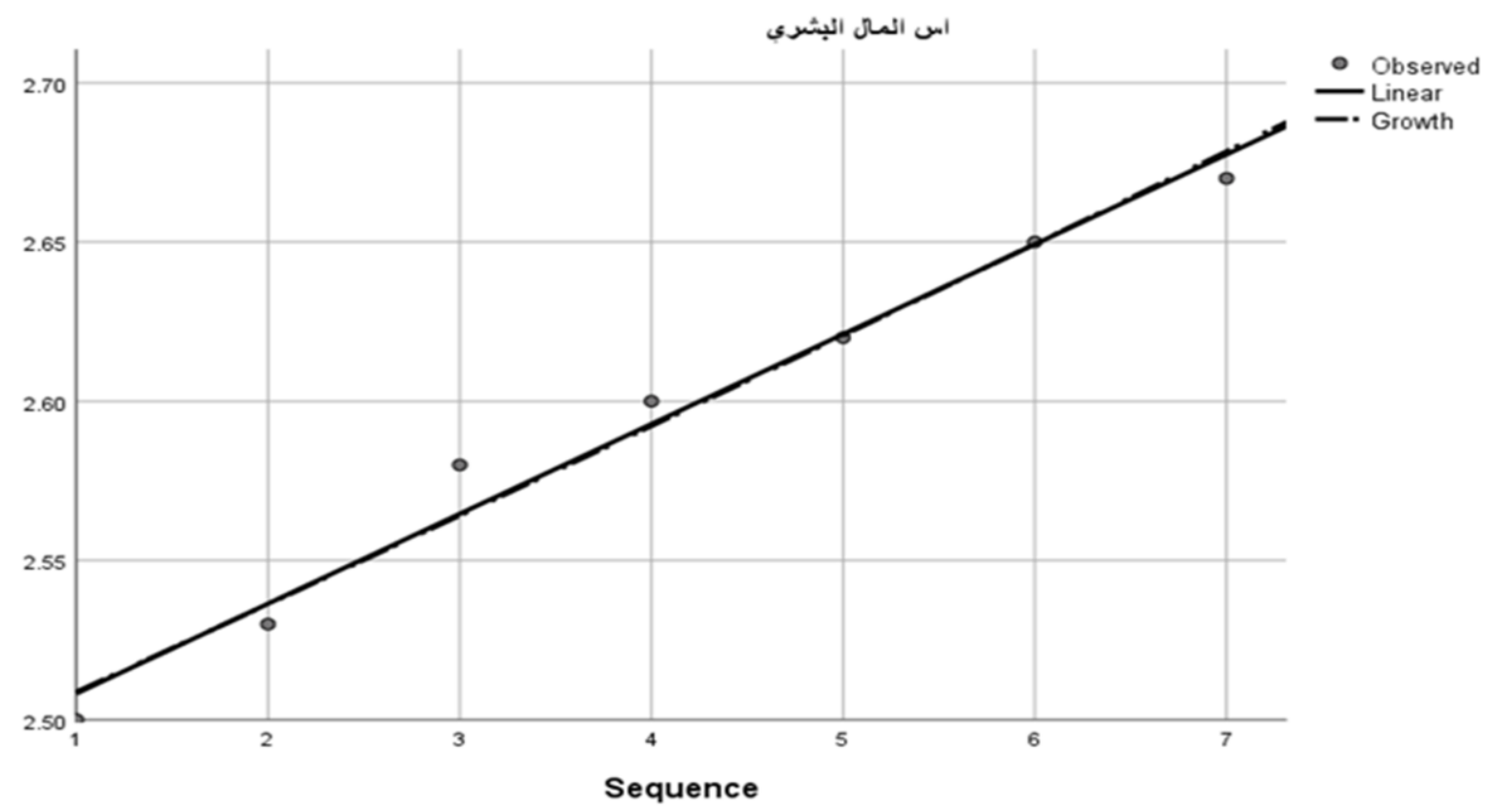

Figure 2. The growth and direction of the human head index

\section{The Results of the Simple Linear Regression Analysis}

Tables 5 and 6 shows the results of the analysis of the simple linear decline of the relationship between the human capital index and the knowledge economy index in Saudi Arabia during the period 2010-2020 Coefficients

Table 5. Dependent variable: Knowledge Economy Arabia

\begin{tabular}{|c|c|c|c|c|c|c|}
\hline \multirow[b]{2}{*}{ Model } & & \multicolumn{2}{|c|}{$\begin{array}{l}\text { Unstandardized } \\
\text { Coefficients }\end{array}$} & \multirow{2}{*}{$\begin{array}{c}\text { Standardized } \\
\text { Coefficients } \\
\text { Beta }\end{array}$} & \multirow[b]{2}{*}{$\mathrm{T}$} & \multirow[b]{2}{*}{ Sig. } \\
\hline & & B & $\begin{array}{l}\text { Std. } \\
\text { Error }\end{array}$ & & & \\
\hline 1 & (Constant) & -991.227 & 447.362 & & -2.216 & 0.091 \\
\hline & $\begin{array}{l}\text { rsmoney } \\
\text { human } \\
\text { beings }\end{array}$ & 388.543 & 171.486 & 0.750 & 2.266 & 0.008 \\
\hline
\end{tabular}

Table 6. The relationship between the human capital index

\begin{tabular}{cccc}
\hline & \multicolumn{3}{c}{ Model Summary } \\
\hline & Adjusted R & Std. Error of the \\
R Square & Square & Estimate & Durbin-Watson \\
0.562 & 0.453 & 19.31279 & 2.265 \\
A. Predictors: (Constant), human capital & \\
b. Dependent Variable: ID Economy & \\
\hline
\end{tabular}

It is obvious from the results of the statistical analysis shown in Tables 5 and 6 that there is a moral dimension between the human capital index and the Knowledge Economy Index of Saudi Arabia, the value of the identification coefficient. 
Table $\mathrm{R}^{2}$ equals ( 0.56 and indicates that investing in human capital by $56 \%$ positively affects the promotion of the Kingdom's integration into the knowledge economy at the same percentage level. The moral of this relationship was confirmed by the F test where its calculated value was $=5.134$ as in Table 5 with a moral level of 0.008 . Since it is less than 0.01, this indicates the whole morale of the model.

The analysis also shows the existence of the expulsion relationship between the independent variable HCI and the KEI, where the value of the independent variable coefficient was 388.5 and indicates the value of the estimated $t$ value of 2.266 with a moral level of 0.008 less than 0.01 , which confirms the morale of the statistical variable. Based on the results of the statistical analysis in Table 6, the simple linear regression equation of the study variables can be written as follows:

\section{Conclusions and Recommendations}

The study is a preliminary attempt by the researcher to measure the impact of human capital in promoting the integration of countries in the knowledge economy by applying to Saudi Arabia setting as a model using published and available data on the variables of the study. It can be concluded that many challenges are affecting KSA to shift towards the knowledge economy. They include the need to pay attention to the available development. the capital of human beings in proportion to it is the vanguard of the knowledge society and cross the infrastructure for the development renaissance, and this requires an increased interest in education, training, education, culture, scientific research.

- The knowledge economy is based mainly on the element of knowledge and the use of the human mind to employ research tools

Development and available economic resources

- The results of the statistical analysis showed a direct relationship with a statistical dimension between human capital and the knowledge economy index, which shows that Saudi Arabia is focusing heavily on the need for human capital because it has an active role in promoting the knowledge economy and applying the requirements of integration into the knowledge economy.

- The study concluded through previous analysis that the knowledge economy depends mainly on the element of knowledge and the use of the human mind to employ the means of research and development and the economic resources available.

- Saudi Arabia has taken appreciable steps to shift towards the knowledge economy through good policies and comprehensive plans to support this, as evidenced by the steady growth rate of the KEI during the study period.

Based on the results of the study, the following is recommended:

Emphasizing the importance of all human capital and investment in it, which leads to increased economic efficiency and economic growth through increased knowledge and experience of individuals.

The government's policy of "eliminating the negative impact of the economic and social system" was a key factor in the development of the economy.

- Increased research and development spending and human element training can help better the knowledge economy and human capital.

- Expanding the implementation of the kingdom's huge investment projects aimed at diversifying the economic base and achieving balanced regional development in all regions of the Kingdom, which paves the way for a knowledge-based economy.

\section{References}

Adnan, S. (2017). Measure of the response of human capital to investment in it selements. Ghela Administrative, and Economic Sciences, 23(100).

Ahmed, B. H. C. (2014). Indicators of measuring the role of universities in the knowledge economy: proposed model: reference to the Saudi economy. Journal of Business Research, (2). Retrieved from http://search.mandumah.com/Record/753298

Ahmed, N. A. (2010). The developmental importance of human capital and the role of education. Journal of Human Science, 7(44).

Amal, A. S., Suad, J. K., \& Sands, J. S. (2014). Knowledge economy and its importance in human development in Iraq. Research Submitted to the Third Scientific Cconference of the Faculty of Management and Economics 
University of Qadisiyah-Sweat.

Annaba, \& Qusi, S. (2019, August). The availability of human capital dimensions in the context of the knowledge economy - field study in the regional directorate of the Algerian insurance and reinsurance company (CAAR). Ramah Research and Studies, (34).

Dawi, A. S., \& Hamdi, A. A. Q. (2013). The role of human capital development in the integration of business organizations based on the economic suppall. The 12th Annual International Scientific Conference for Business entitled: Human Capital in the Knowledge Economy. Jordan, Zaytouna University.

Hanushek, E. A., \& Woessmann, L. (2010). Education and economic growth. Economics of Education, 60-67.

Kamal, M., \& Issa, K. (2006, June). Integration of Arab economies into the economy of knowledge and barriers. Journal of North African Economics, (4), University of Biskra, Algeria.

Kanda, Z., \& Bouqum, M. (2018). Integration into the knowledge economy: between the requirements and indicators of the presidents. Journal of Financial and Business Economics, (6).

Maggie, H. O. (2019). The model of the knowledge economy in light of the challenges of Saudi Arabia. National Education Portal - Research and Studies. Retrieved from http://tarbiagate.com/\%D9\%86\%D9\%85\%D9\%88\%D8\%B0\%D8\%AC/

McClelland, S. D. (2002). A training needs assessment for the united way of Dunn County Wisconsin. The Graduate School University of Wisconsin-Stout, The Graduate School University of Wisconsin-Stout. Report Number TRHRD-735, pp. 1-51.

Nadia, S. M., \& Hashim, M. S. (2013). Intellectual capital is the pillar of the transition to the knowledge economy. The Annual International Business Conference on Human Capital in the Knowledge Economy, Zaytouna University, Jordan.

Nasser, M., \& Samira, A. S. (2016). Distinguished the organization's performance in the context of the knowledge economy: an introduction to investment in human capital. Faculty of Economics and Business and Management Sciences Mohammed Khudhair University.

Nayef, M. S. (2018). Curriculum and knowledge economy: Saudi Arabia and its efforts, and its orientation towards the knowledge Retrieved from https://shms-prod.s3.amazonaws.com/media/editor/148732_hW82Y67.pdf

Nurunnabi, M. (2017). Transformation from an oil-based economy to a knowledge-based economy in Saudi Arabia: The Direction of Saudi Vision 2030. Journal of the Knowledge Economy, 8(2), 536-564.

Ramedi, B., Malwa, M., \& Salami, A. (2018). The impact of human capital on the sustainability of competitive advantage in the age of the knowledge economy (case study: Egyptian tourism companies). International Conference on the Importance of Human Resources Development in the Digital Economy, The Algerian People's Democratic Republic - Informer of Economic and Human Development in Algeria. Retrieved from https://www.researchgate.net/publication/327681007

Sahanin, M., \& Dani, E. K. A. (2017). The role of the knowledge economy in achieving sustainable development. Algerian Journal of Economics and Management, (9), 2017.

Sundus, J. S., \& Shatha, S. D. (2018). Human money and its role in promoting the indicators of the knowledge economy and meeting the needs of the labor market in Iraq. Jihan University Journal, (2), Part (C).

United, N. (2007). Analysis of performance and assessment of growth and productivity in the escwa region. Economic, and Social Commission for Western ASIA, Fifth Issue, New York.

\section{Copyrights}

Copyright for this article is retained by the author(s), with first publication rights granted to the journal.

This is an open-access article distributed under the terms and conditions of the Creative Commons Attribution license (http://creativecommons.org/licenses/by/4.0/). 